\title{
Single-session expectancy challenge with young heavy drinkers on holiday
}

Citation for published version (APA):

van de Luitgaarden, J., Wiers, R. W. H. J., Knibbe, R. A., \& Candel, M. J. J. M. (2007). Single-session expectancy challenge with young heavy drinkers on holiday. Addictive Behaviors, 32(12), 2865-2878. https://doi.org/10.1016/j.addbeh.2007.04.023

Document status and date:

Published: 01/01/2007

DOI:

10.1016/j.addbeh.2007.04.023

Document Version:

Publisher's PDF, also known as Version of record

Document license:

Taverne

Please check the document version of this publication:

- A submitted manuscript is the version of the article upon submission and before peer-review. There can be important differences between the submitted version and the official published version of record.

People interested in the research are advised to contact the author for the final version of the publication, or visit the DOI to the publisher's website.

- The final author version and the galley proof are versions of the publication after peer review.

- The final published version features the final layout of the paper including the volume, issue and page numbers.

Link to publication

\footnotetext{
General rights rights.

- You may freely distribute the URL identifying the publication in the public portal. please follow below link for the End User Agreement:

www.umlib.nl/taverne-license

Take down policy

If you believe that this document breaches copyright please contact us at:

repository@maastrichtuniversity.nl

providing details and we will investigate your claim.
}

Copyright and moral rights for the publications made accessible in the public portal are retained by the authors and/or other copyright owners and it is a condition of accessing publications that users recognise and abide by the legal requirements associated with these

- Users may download and print one copy of any publication from the public portal for the purpose of private study or research.

- You may not further distribute the material or use it for any profit-making activity or commercial gain

If the publication is distributed under the terms of Article $25 \mathrm{fa}$ of the Dutch Copyright Act, indicated by the "Taverne" license above, 


\title{
Single-session expectancy challenge with young heavy drinkers on holiday
}

\author{
Jade van de Luitgaarden ${ }^{\mathrm{a}, *}$, Reinout W. Wiers ${ }^{\mathrm{b}, 1}$, \\ Ronald A. Knibbe ${ }^{\mathrm{a}, 2}$, Math J.J.M. Candel ${ }^{\mathrm{c}, 3}$ \\ a Maastricht University, Faculty of Health Sciences, Department of Medical Sociology, \\ P.O. Box 616, 6200 MD, Maastricht, The Netherlands \\ ${ }^{\mathrm{b}}$ Maastricht University, Faculty of Psychology, Department of Experimental Psychology, \\ P.O. Box 616, 6200 MD, Maastricht, The Netherlands \\ ${ }^{\mathrm{c}}$ Maastricht University, Faculty of Health Sciences, Department of Methodology \& Statistics, \\ P.O. Box 616, 6200 MD, Maastricht, The Netherlands
}

\begin{abstract}
Expectancy challenges (ECs) were used to change alcohol expectancies and alcohol consumption in young heavy drinking men (age 16-24) on holiday. The intervention took place in community centers and bars. Alcohol expectancies and consumption were assessed with paper and pencil measures prior to the intervention $(N=301)$ and 2 days afterwards (EC: $n=178$; controls: $n=86$ ). Six weeks after the EC, participants were interviewed by telephone (EC: $n=163$; controls: $n=71$ ). The intervention resulted in an increase in sedation expectancies in the EC group. Furthermore, the EC led to a differential reduction in alcohol consumption on a night out at the six-week posttest in the heaviest drinkers only. The reduction in alcohol consumption on a night out was not mediated by the change in sedation expectancies. These findings suggest that further research on the mechanisms of change is necessary before a single-session EC may be used in a real-life prevention setting.
\end{abstract}

(C) 2007 Elsevier Ltd. All rights reserved.

Keywords: Expectancy challenge; Alcohol; Mediation; Prevention; Youth

\footnotetext{
* Corresponding author. Tel.: +31 43 3882376; fax: +31 433884169 .

E-mail addresses: J.vandeLuitgaarden@ZW.unimaas.nl(J.van de Luitgaarden), R.Wiers@psychology.unimaas.nl (R.W.Wiers), R.Knibbe@ZW.unimaas.nl (R.A. Knibbe), Math.Candel@stat.unimaas.nl (M.J.J.M. Candel).

1 Tel.: +31 43 3881935; fax: +31 433884196 .

2 Tel.: +31 43 3882282; fax: +31 433884169 .

3 Tel.: +31 43 3882273; fax: +31 433618388 .
}

0306-4603/\$ - see front matter (C) 2007 Elsevier Ltd. All rights reserved. doi:10.1016/j.addbeh.2007.04.023 


\section{Introduction}

Many young people on holiday in seaside camping resorts in the Netherlands drink heavily. On average, young men drink 22 and young women drink 9 Dutch standard drinks per day, (Lemmers, Willems, Thijssen, \& Osterman, 1998), which, independent of type of beverage, contain $10 \mathrm{~g}$ of alcohol (Knibbe \& Bloomfield, 2000). During their holiday, many drink throughout the day (Pos, Knibbe, \& Lemmers, 2001). This binge drinking episode usually lasts 1 to 2 weeks, in which several health risks are faced, varying from alcohol-related falls and traffic accidents to alcohol poisoning.

Many studies have shown correlations between expectancies and alcohol consumption (see Goldman, Del Boca, \& Darkes, 1999). Positive expectancies (e.g. sociability, assertiveness, tension reduction) have been shown to predict current (Sher, Walitzer, Wood, \& Brent, 1991) and future (Sher, Wood, Wood, \& Raskin, 1996; Stacy, Widaman, \& Marlatt, 1990) alcohol consumption in a variety of age groups and drinking populations (Leigh \& Stacy, 2004). Indications exist that negative alcohol expectancies (e.g. lower self-confidence, cognitive and motor problems, negative mood) also contribute to drinking decisions (Leigh \& Stacy, 2004). One can also make a distinction between expectations of arousal (e.g. funny, energetic, horny) and sedation (e.g. sleepy, intoxicated, woozy; Goldman et al., 1999). Heavy drinking is associated with holding relatively strong positive-arousal expectancies, while stronger negative and sedation expectancies are associated with lower levels of drinking. On the basis of this correlation, Darkes and Goldman (1993) developed an "expectancy challenge" (EC) aimed at reducing positive arousal expectancies, which in turn should lead to a decrease in alcohol consumption. In the social expectancy challenge session (Darkes \& Goldman, 1993) male college students were brought together in a bar-lab, where they received a glass of vodkatonic or a placebo drink. A game (Pictionary) was played during drinking. Similarly, a week later another EC session took place, in which expectations of sexual enhancement after drinking alcohol (or placebo) were the focus of attention. In both sessions, all members were asked to write down who they thought had drunk alcohol after the games ended. Judgements were made on the basis of subjects' behaviour. Many drinkers were wrongly identified as non-drinkers and vice versa. These discrepancies were used to discuss the differences between physical and expectancy effects of alcohol. Alcohol results in interoceptive stimuli (e.g. dizziness) and molecular and motor changes (e.g. a person's posture). Alcohol expectancies can also appear without drinking alcohol (Goldman, Brown, \& Christiansen, 1987), because drinking usually takes place in a particular context (e.g. party, disco). Results of the EC were compared with a traditional college prevention program and with an assessment-only group. Only the EC significantly reduced positive social and sexual expectancies and led to a decrease in alcohol consumption in heavy drinkers. The EC is one of the promising interventions with young people (Larimer \& Cronce, 2002).

Since 1993, many studies using the EC have been conducted. Some studies applied the EC to women as well (e.g. Corbin, McNair, \& Carter, 2001; Dunn, Lau, \& Cruz, 2000; Musher-Eizenman \& Kulick, 2003; Wiers, Van de Luitgaarden, Van den Wildenberg, \& Smulders, 2005), other studies reduced the number of sessions in the EC from two to one (e.g. Corbin et al., 2001; Wiers et al., 2005). Furthermore, some 'information-only' ECs were done, in which no actual alcohol was consumed (Corbin et al., 2001; Jones, Silvia, \& Richman, 1995). In general, ECs succeeded in reducing alcohol consumption in male college students (Darkes \& Goldman, 1993, 1998; Wiers et al., 2005). In women, reductions in positive alcohol expectancies were demonstrated, but no differential reductions in alcohol use were achieved (e.g. Wiers et al., 2005). Multi-session ECs may result in larger reductions in positive-arousal expectancies and 
alcohol consumption than single-session protocols (Darkes and Goldman, 1993, 1998; Wiers, 2002), however single-session ECs are easier conducted as an intervention in real-life settings and resulted in equally large effects (at least in one study, Wiers et al., 2005).

In 2002, we conducted a first pilot study in which the feasibility of a single-session EC with youth on holiday was shown (Van de Luitgaarden, Wiers, Knibbe, \& Boon, 2006). This was the first EC conducted in a real-life setting. In this study we used an optimized version of this EC. Only male participants between the ages of 16 and 24 were included, because previous experience had taught us women are much more difficult to recruit and drink much less on average (Van de Luitgaarden et al., 2006). Participants were recruited in seaside camping resorts in the Netherlands. We hypothesized a decrease in positive-arousal expectancies as a result of the EC, and an increase in negative-sedation expectancies. Furthermore, we investigated whether a change in expectancies had caused a change in alcohol consumption (mediation analysis). Partial mediation was previously demonstrated by Wiers et al. (2005), in other EC studies mediation was not formally tested (Jones, Corbin, \& Fromme, 2001; Wiers, 2002).

\section{Methods}

\subsection{Participants}

Young men ( $N=301$, mean age 17.8 years; minimum age 16.0 years; the minimum legal drinking age) spending a vacation at one of two seaside vacation destinations were recruited by trained students ('peers'). Most participants $(96.0 \%)$ were on holiday with friends, without their parents or partner. Participants reported drinking on average 23.8 Dutch standard-drinks per day during vacation and 32.1 standard-drinks in a regular week when not on vacation. Young men in our study are very heavy drinkers compared to the average consumption of Dutch young men aged 16 to 24 (15.5 standard drinks per week; Van Dijck \& Knibbe, 2005), and compared to recommendations (2-3 drinks max. per day, at least two alcohol-free days a week).

The study was presented somewhat differently to participants in the EC and control group. 'Peers' approached potential EC participants $(n=186)$ at camping sites on the Isle of Terschelling. Young men were asked if they would like to participate in a study on alcohol, which would involve drinking 2 bottles of Smirnoff Black Ice (a popular premix). They were instructed to be sober for the meeting. They were told that they would receive $€ 7.50$ after completing the second measurement 2 days later and that they would be interviewed by telephone 2 months later. Young men spending a vacation at the Isle of Texel constituted the control group $(n=115)$. Controls were invited to participate in a study on alcohol, which would involve filling out questionnaires twice and being interviewed over the telephone. They received $€ 5$ for participation, somewhat less than EC participants because of a smaller time-investment. A quasiexperimental design was chosen to ensure that a sufficient number of participants could be recruited within the given space of time, and had the additional advantage that experimental and control subjects were unlikely to come into contact with each other.

\subsubsection{Attrition}

Two days after the initial assessment, 37 participants dropped out because the 'peers' were unable to contact them for filling out further questionnaires. Six weeks after the EC, an additional 30 participants could not be reached for the telephone interview (see Table 1). To examine whether participants who did 
Table 1

Design of the study, and questionnaires used

\begin{tabular}{|c|c|c|c|c|}
\hline & $\begin{array}{l}\text { T0 Pretest EC: } n=186 \\
\text { Control: } n=115\end{array}$ & $\begin{array}{l}\text { T1 Directly after EC } \\
\text { EC: } n=185\end{array}$ & $\begin{array}{l}\mathrm{T} 2+2 \text { days EC: } n=178 \\
\text { Control: } n=86\end{array}$ & $\begin{array}{l}\text { T3+6 weeks EC: } n=163 \\
\text { Control: } n=71\end{array}$ \\
\hline \multirow[t]{3}{*}{ Questionnaire } & 24-hour Drinking Diary & $\begin{array}{l}\text { VAS-Expectancies } \\
\text { Questionnaire }\end{array}$ & 24-hour Drinking Diary & Drinking Questionnaire \\
\hline & Drinking Questionnaire & & $\begin{array}{l}\text { VAS-Expectancies } \\
\text { Questionnaire }\end{array}$ & $\begin{array}{l}\text { VAS-Expectancies } \\
\text { Questionnaire }\end{array}$ \\
\hline & $\begin{array}{l}\text { VAS-Expectancies } \\
\text { Questionnaire } \\
\text { Demographics } \\
\text { Questionnaire }\end{array}$ & & & \\
\hline
\end{tabular}

not complete all measurements differed from those who did, logistic regression analyses ${ }^{4}$ were conducted for dropout 2 days and 6 weeks after the initial assessment. Significantly more control participants dropped out after 2 days $(p<.001)$. In addition, both age and baseline vacation consumption showed a positive association with dropout at that point in time $(p<.05$ and $p<.01$, respectively). Other variables did not predict attrition after 2 days. Attrition 6 weeks after the EC could not be predicted from any of the variables.

\subsection{Procedures}

\subsubsection{Design}

The study was conducted as a repeated measures design over an approximate 2-month time interval with one intervention session held in the EC group. The control group received assessment only. Table 1 outlines the design of the study and details the questionnaires used. Trained 'peers' led all EC sessions. In total, 16 ECs were conducted with 10-15 young men participating in each session. The team of peers consisted of 4 female students and 1 male student. Session leadership changed from session to session. A graduate student supervised all ECs. All components of the EC were covered in every EC session. The EC was a modified version of the procedure used by Darkes and Goldman (1993). Changes in the protocol included telling participants everyone would receive alcohol (active deception, Marlatt \& Rohsenow, 1980, as in Wiers et al., 2005), using only one session instead of two and omitting the game in which attractiveness of pictures of women was rated. Furthermore, we used a premix instead of vodka-tonic, because the Dutch Alcohol Licensing and Catering act forbids serving vodka-tonic to persons younger than 18 years, while a premix can be served to persons of 16 years and older.

\subsubsection{Expectancy challenge}

Participants received a nametag and were breathalysed upon entering. They then filled out informed consent and the baseline questionnaire. The actual intervention started with asking the participants to give

\footnotetext{
${ }^{4}$ Results were checked by multi-level logistic regression analyses in which attrition was analysed taking into account possible data dependencies due to participants receiving treatment in subgroups. There was a lack of variability at the level of the subgroup in the EC condition, thus confirming the results of the initial logistic regression analyses, in which the effects of nesting in subgroups were disregarded.
} 
associations to the sentence "Alcohol makes me...". The session leader wrote all associations on a flipover. Then, half of all participants received two alcoholic drinks, while the other half received placebo beverages. The placebo beverage was a low-alcoholic mix of $140 \mathrm{cc}$ Spa Clear Citrus, $80 \mathrm{cc}$ tonic and 55 cc Smirnoff Black Ice. The placebo drink contained 1\% alcohol ( $<3 \mathrm{~g}$ of alcohol per bottle). The alcoholic mixed drink consisted of $240 \mathrm{cc}$ Smirnoff Black Ice and $35 \mathrm{cc}$ tonic and contained 4\% alcohol ( $\pm 11 \mathrm{~g}$ of alcohol per bottle). Tonic was added to the alcoholic Smirnoff Black Ice drink to make the taste of the alcoholic and placebo drink more alike. All participants received two refilled Smirnoff Black Ice bottles of $275 \mathrm{cc}$ each. Half received two bottles containing alcohol; the other half two placebo bottles. Half of the participants received bottles with straws, independent of the contents of the bottle. This was done to divert attention away from the taste of the drinks. Many participants presumed the straws were the experiment, and therefore did not focus on the taste of the drinks. The tables had trays with salted peanuts and potato crisps on them to stimulate participants' thirst. After the drinks were handed out, the group was divided in two teams. Participants engaged in a game of Pictionary, in which team members graphically illustrate clues on a flip-over in an attempt to communicate a secret phrase to other team members. Sexually charged secret phrases were used, which were a useful leg up to the sexual alcohol expectancies discussed later. After the game was completed (15 min), it was disclosed that only half of all subjects had received (about) two standard drinks of alcohol, while the other half had received almost no alcohol. Participants were asked to list the drinkers and to motivate their choice. In every EC, several misclassifications were made. Identification errors were used to discuss alcohol expectancies. The main message was that expectancies are often the cause of behavioural effects after drinking, instead of pharmacological properties of alcohol. Special attention was given to social and sexual alcohol expectancies. The information was closely modelled after the original protocol. After the EC, participants filled out another questionnaire (see Table 1). Furthermore, appointments were made to fill out questionnaires at the campsite 2 days later. Participants were breathalysed and signed a form stating that they were aware of their alcohol-level and would be cautious in choosing their activities and transportation the next few hours.

\subsubsection{Assessment-only}

Control participants filled out an informed consent form and baseline measures at the camping site immediately after they agreed to participate in the study. No group meetings were held, questionnaires were filled out individually. Appointments were made to collect measures 2 days later.

\subsection{Measures}

\subsubsection{Demographics Questionnaire}

Background characteristics of participants were measured with a self-devised demographics questionnaire. Questions addressed age, housing situation, romantic relationships, job, peer group size and composition, length of stay, income and education.

\subsubsection{Visual Analogue Scale (VAS) of arousal-sedation expectancies}

Alcohol expectancies were measured by the VAS-expectancies questionnaire (Wiers, Van Woerden, Smulders, \& De Jong, 2002; Wiers et al., 2005). We used a modified version in which expectations for a high dose of alcohol were specifically targeted (see Van de Luitgaarden et al., 2006), because these are the best predictor of alcohol use in heavy drinking young males (Wiers, Hoogeveen, Sergeant, \& Gunning, 
1997). The VAS-arousal/sedation expectancies scale consists of twelve arousal-sedation attributes. Participants indicated on a 7-point VAS scale to what extent they agreed with each of twelve statements (e.g., "after drinking 6 or more glasses of alcohol I become excited"). The VAS-expectancies questionnaire was most suitable for our study because it is relatively short, includes equal numbers of items describing desirable and undesirable effects (see Leigh \& Stacy, 1993) and reduces memory-effects that can occur with repeated administrations (Schwartz, 1999). Furthermore, it was previously successful in detecting changes in expectancies as a result of an EC procedure (Wiers et al., 2005) and in predicting actual behaviour under the influence of alcohol (Bot, Engels, \& Knibbe, 2005). Internal consistencies as well as test-retest reliabilities of this questionnaire are satisfactory (Van de Luitgaarden et al., 2006; Wiers et al., 2005). In the present study, internal consistencies (Cronbach's $\alpha$ ) of the arousal and sedation subscales were .72 and .67 , respectively. Test-retest reliabilities (controls-only) were .57 for the sedation subscale and .74 for the arousal subscale.

\subsubsection{Drinking Questionnaire}

Alcohol consumption before and after the vacation was measured by questions about drinking behaviour on typical week-days, frequency of going out in the weekend, number of glasses consumed while going out and number of glasses consumed prior to going out (at home or at a friend's house).

\subsubsection{Drinking Diary}

At baseline, participants were asked if they had drank any alcohol the previous day, and if the answer was 'yes', if they had drank alcohol in the morning, in the afternoon, in the evening or at night. They were also asked to report where the alcohol was consumed (e.g. pub/disco, camping site, beach) and how much standard glasses of alcohol they drank in each location at each time of day. Two days after the EC, both control and EC participants filled out the Drinking Diary over the previous day.

\subsection{Analyses}

Effects of the EC on scores on the VAS-expectancies questionnaire were analyzed with multiple regression analyses. Expectancies 2 days after the EC (short-term) and expectancies 6-8 weeks after the EC (long-term) were dependent variables. Condition was the independent variable, and covariates were included (age, money, number of friends with whom one spends the holiday, education, baseline alcohol consumption on a night out and during ordinary week and weekend days, as well as baseline arousal and sedation expectancies). Inter-correlations between independent variables were all below .70, excluding collinearity problems. Paired $t$-tests were performed to investigate if expectancies had changed immediately after the intervention in the EC group. It was hypothesized that positive-arousal expectancies should decrease and negative-sedation expectancies increase as a result of the EC. Furthermore, we tested the effect of the intervention on alcohol consumption. Alcohol consumption on holiday 2 days after the EC, and alcohol use on a regular night out 6-8 weeks after the EC were dependent variables ${ }^{5}$ (in separate analyses). Again, condition

\footnotetext{
5 Indices of alcohol consumption showed deviances from normality. Therefore, all were log transformed with the following formula: $\ln A l c U s e=\ln ($ AlcUse +1$)$, where one is added to make the inclusion of non-drinkers possible. Transformations may make interpretation of results more difficult (Stevens, 1992), therefore non-transformed indices of alcohol use are reported here. However, all results were confirmed with log-transformed alcohol variables, and the pattern of results was the same.
} 
was an independent variable, and the fore mentioned covariates were included (baseline holiday consumption was included as an additional covariate in the analysis of consumption on holiday 2 days after the intervention). We hypothesized a reduction in alcohol consumption in the EC group. Previous studies indicated the impact of the intervention may be related to participants' level of baseline consumption (Darkes \& Goldman, 1998), therefore we tested interactions between baseline drinking level and condition.

EC participants were nested within subgroups of 10-15 young men who received the intervention at the same time, therefore control multi-level analyses were performed (with MlwiN version 2.02), which tested the effects of the intervention taking into account possible data dependencies within subgroups. All analyses demonstrated a lack of random variability at the level of the subgroup in the EC condition, thus confirming the results of the multiple regression analyses, in which the effects of nesting in subgroups were disregarded. Finally, mediation analyses (Baron \& Kenny, 1986) were performed using AMOS 5.0 structural equation modelling (SEM) software.

\section{Results}

\subsection{Baseline drinking and expectancies}

Table 2 presents demographic and background variables of our sample. EC participants were significantly older than controls at baseline $F(1,299)=4.44, p<.05$. Age, money, number of friends with whom one spends the holiday, education, baseline alcohol consumption on a night out and during ordinary week and weekend days, as well as baseline arousal and sedation expectancies were included as covariates in further analyses.

Table 2

Means and standard deviations by condition for demographic and background variables

\begin{tabular}{|c|c|c|c|c|c|c|c|}
\hline \multirow[b]{2}{*}{ Variable } & \multicolumn{2}{|c|}{$\mathrm{EC}(n=186)$} & \multicolumn{2}{|c|}{$\begin{array}{l}\text { Control } \\
(n=115)\end{array}$} & \multicolumn{2}{|c|}{$\begin{array}{l}\text { Overall sample } \\
(N=301)\end{array}$} & \multirow[t]{2}{*}{$p$} \\
\hline & $M$ & SD & $M$ & SD & $M$ & SD & \\
\hline Age, in years & 17.98 & 1.54 & 17.57 & 1.79 & 17.83 & 1.65 & .04 \\
\hline $\begin{array}{l}\text { Alcohol consumption in } 24 \mathrm{~h} \text { before intervention, in Dutch standard } \\
\text { glasses }\end{array}$ & 24.27 & 13.14 & 22.35 & 11.83 & 23.55 & 12.68 & ns \\
\hline Mean alcohol consumption on a night out, in Dutch standard glasses & 14.98 & 6.44 & 15.29 & 8.98 & 15.10 & 7.50 & ns \\
\hline Amount of money to spend per month, in Euros & 296.43 & 233.95 & 246.36 & 239.39 & 277.01 & 236.93 & ns \\
\hline Education level $^{\mathrm{a}}$ & 2.00 & - & 3.00 & - & 2.00 & - & ns \\
\hline Size of circle of friends on holiday (excl. themselves) & 6.20 & 4.37 & 6.34 & 4.99 & 6.25 & 4.61 & ns \\
\hline $\begin{array}{l}\text { Total alcohol consumption from Friday to Sunday in Dutch Standard } \\
\text { glasses }\end{array}$ & 26.10 & 14.47 & 25.55 & 19.06 & 25.87 & 16.32 & ns \\
\hline $\begin{array}{l}\text { Total alcohol consumption from Monday to Thursday in Dutch standard } \\
\text { glasses }\end{array}$ & 6.33 & 7.87 & 8.03 & 11.22 & 6.97 & 9.29 & ns \\
\hline Alcohol expectancies-Arousal sumscore ${ }^{b}$ & 31.13 & 7.43 & 31.29 & 8.66 & 31.19 & 7.91 & ns \\
\hline Alcohol expectancies-Sedation sumscore ${ }^{c}$ & 21.61 & 6.52 & 20.30 & 6.38 & 21.11 & 6.49 & ns \\
\hline
\end{tabular}

\footnotetext{
${ }^{\mathrm{a}}$ Mode is presented instead of mean, education was coded as $1=$ low education level, $2=$ moderate education level, $3=$ high education level.

${ }^{\mathrm{b}}$ Arousal expectancies were computed as the sum of 7 items measuring arousal expectancies on a 7 point Likert scale.

${ }^{\mathrm{c}}$ Sedation expectancies were computed as the sum of 7 items measuring sedation expectancies on a 7 point Likert scale.
} 


\subsection{Effects of the EC on expectancies}

\subsubsection{Effects on sedation expectancies}

Sedation expectancies of EC participants had increased immediately after the intervention $t(182)=$ $-4.34, p<.001$. Condition significantly predicted VAS-sedation expectancies 2 days after the EC, with sedation expectancies being significantly higher in the intervention group compared to the control group $F(1,259)=12.38, p=.001$. Six weeks after the $\mathrm{EC}$, condition was still a significant predictor of sedation expectancies, $F(1,217)=9.75, p<.01$ (see Fig. 1, T2 and T3).

\subsubsection{Effects on arousal expectancies}

Arousal expectancies of EC participants had not changed immediately after the intervention $(p>.40)$. Condition did not predict VAS-arousal expectancies 2 days after the EC $(p>.50)$, nor did it predict VASarousal expectancies 6 weeks later $(p>.50)$.

\subsection{Effects of the EC on alcohol consumption}

\subsubsection{Alcohol consumption on holiday}

The interaction between alcohol consumption on holiday at baseline and condition was non-significant $(p>.50)$. The regression analysis showed no effect of condition on alcohol consumption on vacation, 2 days after the intervention $(p>.50)$.

\subsubsection{Alcohol consumption on a regular night out}

The interaction between alcohol consumption on a regular night out at baseline and condition was significant $F(1,231)=5.48, p<.05$. Therefore, we performed a median split on baseline consumption levels of the entire sample. Participants who drank 14 standard drinks or less on a 'regular night out' constituted the lower-level drinking group, while participants who drank more than 14 drinks constituted the heaviest drinking group. The regression analyses were done separately for the lower-level drinking group and the heaviest drinking group. Condition was an independent variable, and age, money, number

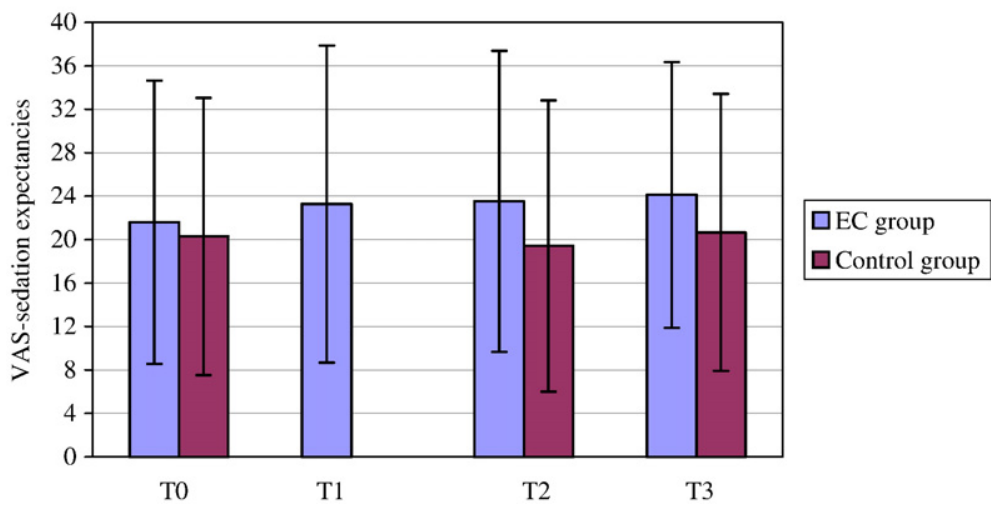

Fig. 1. VAS-sedation expectancies, by condition. Assessments were conducted prior to the intervention (T0), immediately after the intervention (only in the EC group, T1), 2 days after the intervention (T2) and 6 weeks after the intervention (T3). Y error bars depict $95 \%$ confidence intervals. 
of friends with whom one spends the holiday, education, baseline alcohol consumption on a night out and during ordinary week and weekend days, as well as baseline arousal and sedation expectancies were included as covariates. The intervention resulted in a stronger decrease in alcohol consumption on a regular night out in the heaviest drinking EC group compared to the heaviest drinking control group $F$ $(1,96)=7.91, p=.01$ (see Fig. 2). The EC did not result in changes in the lower-level drinking group $(p>.50)$.

\subsection{Correlations between expectancies and alcohol consumption}

We examined correlations between baseline VAS-arousal and sedation expectancies on the one hand, and total alcohol use during week- and weekend days, on a night out, and during vacation on the other hand. VAS-sedation expectancies correlated negatively with alcohol consumption on a night out $(r=-.152, p<.01)$, with total consumption from Monday through Friday $(r=-.121, p<.05)$ and with consumption during the weekend $(r=-.137, p<.05)$. Sedation expectancies did not correlate with alcohol use on holiday. All correlations between arousal expectancies and consumption were nonsignificant ( $p$ 's $>.40)$. Furthermore, alcohol use on holiday correlated positively with consumption on a regular night out $(r=.622, p<.001)$ and with total weekly alcohol consumption when not on vacation $(r=.552, p<.001)$.

\subsection{Mediation analyses}

Mediation was tested in the heaviest drinkers for alcohol consumption on a regular night out 6 weeks after the intervention, using a model specifically proposed for the present design (MacKinnon, 1994; cf. Wiers et al., 2005). Lower-level drinkers were excluded from the analysis because they cannot be expected to show any mediation (no change in drinking). In the present study both the mediator 'sedation expectancies', as well as the outcome variable 'alcohol consumption on a night out' (in the heaviest drinkers of the EC group) were significantly changed by the intervention. The direct pathway from condition to alcohol consumption on a night out during follow-up was significant $(p=.05)$, as well as the direct pathway from condition to post-test sedation expectancies $(p<.05)$. However, the pathway from

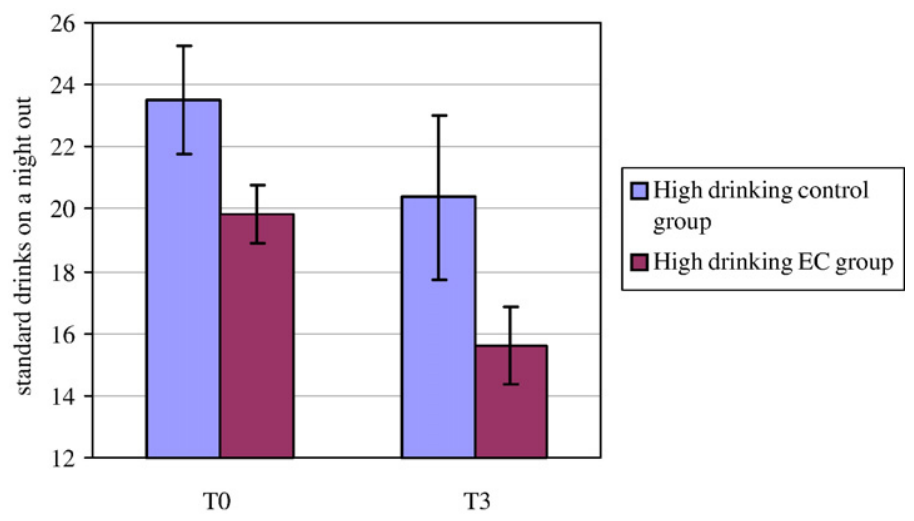

Fig. 2. Alcohol consumption on a regular night out, in the heaviest drinking group, per condition. $\mathrm{T} 0=$ pretest, $\mathrm{T} 3=6 \mathrm{weeks}$ after the intervention. Y error bars depict $95 \%$ confidence intervals. 
post-test sedation expectancies to alcohol consumption at follow-up was non-significant, indicating absence of mediation (Fig. 3a). To test for the possibility that the inclusion of the control group suppressed a mediation effect (Shrout \& Bolger, 2002), a mediation analysis was performed in which controls were

a. Mediation model of alcohol use on a regular night out at 6-week follow-up (heaviest drinkers only; Standardized Bootstrap Estimates)

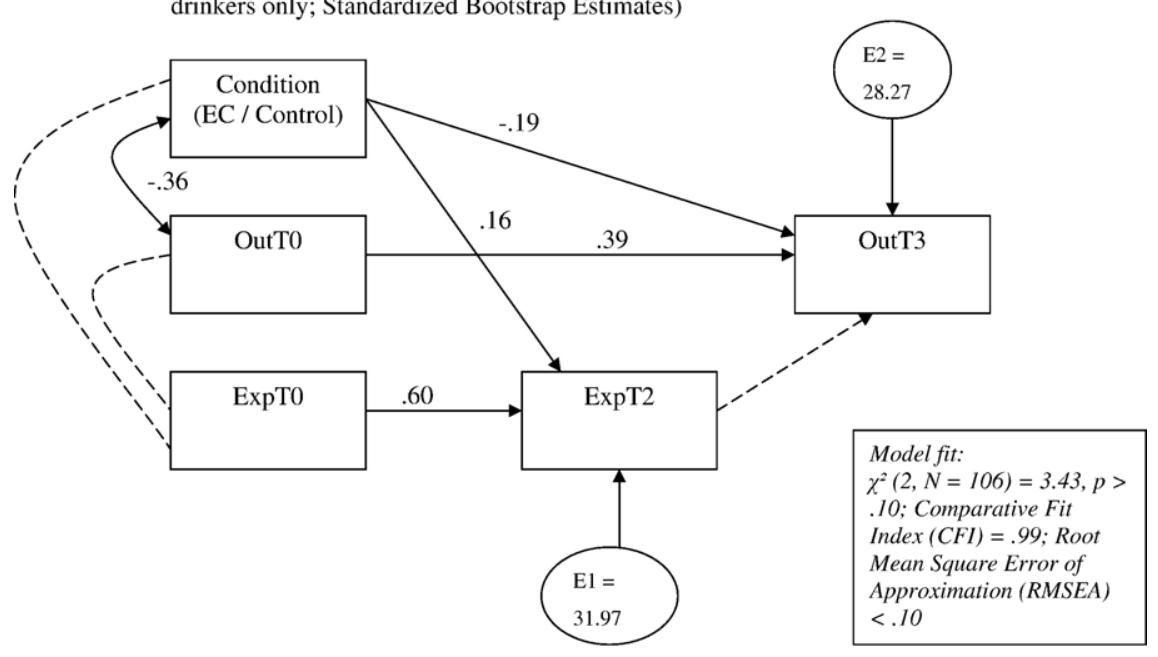

b. Mediation model of alcohol use on a regular night out at 6-week follow-up (heaviest drinking EC participants only; Standardized Bootstrap Estimates)

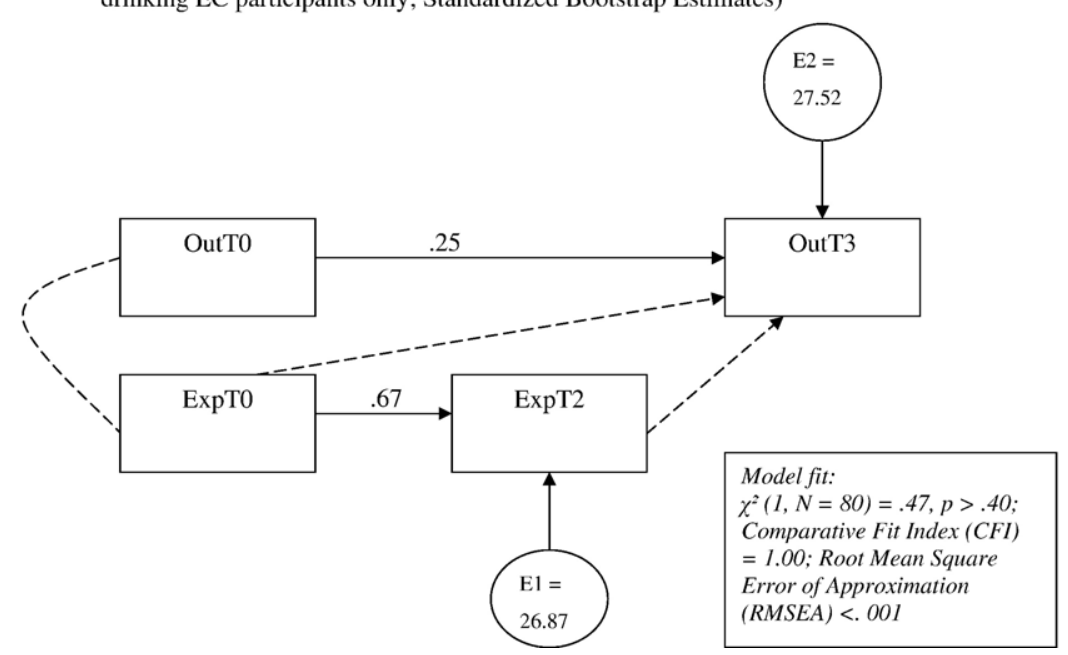

Fig. 3. Mediation analysis of alcohol consumption on a night out 6 weeks after the intervention in the heaviest drinkers. It was tested if the increase in sedation expectancies after the EC mediated the prospective reduction in alcohol use on a night out in the heaviest drinkers 6 weeks later (a). Additionally, mediation was tested in the heaviest drinking EC participants only (b). Drawn lines depict significant paths, dashed lines non-significant paths. Bias-corrected maximum likelihood bootstrap estimates of standardized regression weights are presented for significant paths. The bias-corrected bootstrap method has the best power to detect mediation effects (MacKinnon, Lockwood, \& Williams, 2004). Out=alcohol use on a night out in standard drinks; $\mathrm{Exp}=$ sedation expectancies; $\mathrm{E}=$ estimated error variance; $\mathrm{T} 0=$ pretest, $\mathrm{T} 2=2$ days after the intervention, $\mathrm{T} 3=6 \mathrm{weeks}$ after the intervention. 
excluded (Fig. 3b). However, the direct pathway from sedation expectancies 2 days after the EC to alcohol consumption on a night out at follow-up remained non-significant $(p>.40)$, as well as the pathway from baseline sedation expectancies to alcohol consumption on a night out at follow-up $(p>.10)$. Hence, the EC-induced change in sedation expectancies was not a mediator of the reduction in alcohol consumption in the heaviest drinkers in the EC group during a night out 6 weeks later (Fig. 3).

\section{Discussion}

The findings of our study partly replicate findings from other studies (Darkes \& Goldman, 1993, 1998; Dunn et al., 2000; Wiers et al., 2005). Participants in the EC condition increased their sedation expectancies after the EC, and the heaviest drinking EC participants reduced their alcohol consumption on a regular night out more than control participants. This differential reduction in consumption was small, but significant. The effect size was much smaller $(d=0.12)$ than in previous EC studies $(d=0.67$; Darkes \& Goldman, 1993; Wiers et al., 2005). Furthermore, no mediation of alcohol use by sedation expectancies took place. This is somewhat surprising, because the idea behind the EC is to decrease consumption by changing expectancies. There are several possible explanations for our null finding regarding mediation. First, the test-retest reliabilities of the sedation subscale were fairly low in our sample, while other studies found adequate reliability (Wiers et al., 2005; Van de Luitgaarden et al., 2006). Perhaps, alcohol expectancies in youth on holiday are not stable, but vary over time, causing them to be less predictive of alcohol use in this population. Second, our null finding may add support to questions about the mechanism of change evoked by the EC (cf. B.T. Jones et al., 2001). As other authors have noted, expectancy change is not the sole means whereby drinking might change (Del Boca and Darkes, 2001; Jones et al., 2001; Wiers et al., 2005). It may be that other characteristics of the intervention caused the small change in heavy drinkers (e.g. seeing one's breath alcohol level after drinking). Arousal expectancies did not change after the intervention. To explain this, one could argue that the VASexpectancies questionnaire was inappropriate. Although the test-retest reliabilities of the sedation subscale were indeed rather low in our sample, test-retest reliabilities of the arousal subscale were actually sufficient. It is possible that the intervention simply did not succeed in changing arousal expectancies, perhaps because there was only one session per group and the duration of each session was only 1.5 to $2 \mathrm{~h}$. Similarly, more sessions or a longer duration of the EC may be necessary to change total alcohol consumption in the weekend and consumption from Monday through Friday. It may also be the case that these young men simply drink too heavily for this intervention.

In our previous EC study with youth on holiday, no correlations were found between baseline VASexpectancies and baseline alcohol consumption on a night out and on holiday (Van de Luitgaarden et al., 2006). In the present study, we did find a significant correlation between baseline VAS-sedation expectancies and consumption on a regular night out. This is in line with other studies showing correlations between negative-sedation alcohol expectancies and consumption (see Goldman et al., 1999). However, sedation expectancies did not correlate with alcohol use on holiday, which suggests that drinking behaviour on holiday may be less influenced by these expectancies than alcohol consumption outside the vacation. VAS-arousal expectancies did not correlate with measures of alcohol consumption. We found this in our previous study as well (Van de Luitgaarden et al., 2006), while other studies did find significant correlations between arousal expectancies and consumption with the same VAS-expectancies questionnaire in samples of heavy and light drinkers (Wiers et al., 2002). Possibly, arousal expectancies predict alcohol consumption in beginning drinkers, but lose their predictive value when alcohol use exceeds a certain threshold (in accordance with 
DiChiara's incentive habit theory, cf. Mogg, Field, \& Bradley, 2005). In our study, almost all participants were very heavy drinkers while on holiday. In daily life, they drank approximately the same amount of alcohol as participants in another study (Wiers et al., 2005), which did demonstrate significant correlations between arousal expectancies and alcohol consumption. A related explanation for the lack of correlation could be that arousal expectancies lose their predictive value when they exceed a certain threshold. Nearly all participants in our study had high arousal expectancies.

The present study is one of the largest studies on the effects of the EC. It is also one of the first studies in which the EC was applied to heavy drinkers in a natural setting. A limitation of the present study is the quasiexperimental design. In the analyses, we corrected for differences in background characteristics, however it cannot be completely ruled out that other differences between EC and control group may have been present. Performing an EC with young people on holiday was feasible (Van de Luitgaarden et al., 2006) and a significant increase in sedation expectancies was achieved. The EC caused a small differential reduction in consumption on a regular night out among the heaviest drinkers, but reductions in alcohol use among lower-level drinkers and mediation of alcohol use by expectancies are lacking. Many other single-session ECs found limited results (e.g. Corbin et al., 2001; Van de Luitgaarden et al., 2006). Multiple session ECs may achieve more results, but are too difficult to use with young people on holiday, since the population changes rapidly and no agendas are kept.

It may be that the EC is not particularly suited for application with young people on holiday. The costs of performing the EC are high (see Van de Luitgaarden et al., 2006), relatively few people can be reached, and the effects on consumption have been relatively small. Furthermore, the lack of mediation in our sample suggests that the 'active ingredients' in this EC are not known, which makes application in practice somewhat problematic at this point in time. Future studies should establish if changes in consumption after the EC are caused by changes in expectancies (B.T. Jones et al., 2001). If mediation is confirmed, the EC might be useful in the context of social work, performed with youth at risk in a community centre. In such a situation, multiple EC sessions could be performed because the social worker has an ongoing relationship with these young people. Additionally, it would be easier to provide evidence for the efficacy of the procedure, because there would be more potential for follow-up measurements. Another possible use for the EC would be as a fun, accepted leg up to personal follow-up contact (e.g. Motivational Interviewing). Future studies are needed to evaluate the potential of the EC as a practice-applied intervention.

\section{Acknowledgments}

This study was funded by a 'Healthy Living' grant from the Dutch Organisation for Health Research and Development (ZonMw; grant number 4010.0001).

\section{References}

Baron, R. M., \& Kenny, D. A. (1986). The moderator-mediator variable distinction in social psychological research: Conceptual, strategic, and statistical considerations. Journal of Personality and Social Psychology, 51, 1173-1182.

Bot, S. M., Engels, R. C., \& Knibbe, R. A. (2005). The effects of alcohol expectancies on drinking behaviour in peer groups: Observations in a naturalistic setting. Addiction, 100, 1270-1279.

Corbin, W. R., McNair, L. D., \& Carter, J. A. (2001). Evaluation of a treatment-appropriate cognitive intervention for challenging alcohol outcome expectancies. Addictive Behaviors, 26, 475-488.

Darkes, J., \& Goldman, M. S. (1993). Expectancy challenge and drinking reduction: Experimental evidence for a mediational process. Journal of Consulting and Clinical Psychology, 61, 344-353. 
Darkes, J., \& Goldman, M. S. (1998). Expectancy challenge and drinking reduction: Process and structure in the alcohol expectancy network. Experimental and Clinical Psychopharmacology, 6, 64-76.

Del Boca, F. K., \& Darkes, J. (2001). Is the glass half full or half empty? An evaluation of the status of expectancies as causal agents. Addiction, 96, 1681-1683.

Dunn, M. E., Lau, H. C., \& Cruz, I. Y. (2000). Changes in activation of alcohol expectancies in memory in relation to changes in alcohol use after participation in an expectancy challenge program. Experimental and Clinical Psychopharmacology, 8, 566-575.

Goldman, M. S., Brown, S. A., \& Christiansen, B. A. (1987). Expectancy theory: Thinking about drinking. In H. T. Blane \& K. E. Leonard (Eds.), Psychological theories of drinking and alcoholism (pp. 181-226). NY: Guilford.

Goldman, M. S., Del Boca, F. K., \& Darkes, J. (1999). Alcohol expectancy theory: The application of cognitive neuroscience. In H. T. Blane \& K. E. Leonard (Eds.), Psychological theories of drinking and alcoholism (pp. 203-46) (2nd ed.). NY: Guilford.

Jones, B. T., Corbin, W., \& Fromme, K. (2001). A review of expectancy theory and alcohol consumption. Addiction, 91, 57-72.

Jones, L., Silvia, L., \& Richman, C. L. (1995). Increased awareness and self-challenge of alcohol expectancies. Substance Abuse, 16, 77-85.

Knibbe, R. A., \& Bloomfield, K. (2000). Alcohol consumption estimates in surveys in Europe: Comparability and sensitivity for gender differences. Substance Abuse, 22, 23-38.

Larimer, M. E., \& Cronce, J. M. (2002). Identification, prevention, and treatment: A review of individual-focused strategies to reduce problematic alcohol consumption by college students. Journal of Studies on Alcohol, Supplement, 14, 148-163.

Leigh, B. C., \& Stacy, A. W. (1993). Alcohol outcome expectancies: Scale construction and predictive utility in higher order confirmatory models. Psychological Assessment, 5, 216-229.

Leigh, B. C., \& Stacy, A. W. (2004). Alcohol expectancies and drinking in different age groups. Addiction, 99, $215-227$.

Lemmers, L., Willems, Y., Thijssen, P., \& Osterman, C. (1998). Evaluatie zomercampagne 1997 'Lazer op met je zatte kop' [Evaluation summer campaign 1997 'Bugger off with your boozy talk']. Woerden: NIGZ.

MacKinnon, D. P. (1994). Analysis of mediating variables in prevention and intervention research. In A. Cazares \& L. A. Beatty (Eds.), Scientific methods for prevention intervention research. NIDA Research Monograph No 139. NIH Publication 94-3631 (pp. 127-153). Washington DC: Government printing office.

MacKinnon, D. P., Lockwood, C. M., \& Williams, J. (2004). Confidence limits for the indirect effects. Distribution of the product and resampling methods. Multivariate Behavioral Research, 39, 99-128.

Marlatt, G. A., \& Rohsenow, D. J. (1980). Cognitive processes in alcohol use: Expectancy and the balanced placebo design. In N. K. Mello (Ed.), Advances in substance abuse: Behavioral and biological research (pp. 159-199). Greenwich: JAI Press.

Mogg, K., Field, M., \& Bradley, B. P. (2005). Attentional and approach biases for smoking cues in smokers: An investigation of competing theoretical views of addiction. Psychopharmacology, 180, 333-341.

Musher-Eizenman, D. R., \& Kulick, A. D. (2003). An alcohol expectancy-challenge prevention program for at-risk college women. Psychology of Addictive Behaviors, 17, 163-166.

Pos, S., Knibbe, R., \& Lemmers, L. (2001). Alle dagen feest? Een kwalitatieve studie naar omgevingsinvloeden op het alcoholgebruik van jongeren op vakantie [Party everyday? A qualitative study of environmental influences on young people's alcohol use on holiday]. Woerden/Maastricht: NIGZ/UM.

Schwartz, N. (1999). Self-reports. How questions shape the answers. American Psychologist, 54, 93-105.

Sher, K. J., Walitzer, K. S., Wood, P. K., \& Brent, E. E. (1991). Characteristics of children of alcoholics: Putative risk factors, substance use and abuse and psychopathology. Journal of Abnormal Psychology, 100, 427-448.

Sher, K. J., Wood, M. D., Wood, P. K., \& Raskin, G. (1996). Alcohol outcome expectancies and alcohol use: A latent crosslagged panel study. Journal of Abnormal Psychology, 105, 561-574.

Shrout, P. E., \& Bolger, N. (2002). Mediation in experimental and nonexperimental studies: New procedures and recommendations. Psychological Methods, 7, 422-445.

Stacy, A. W., Widaman, K. F., \& Marlatt, G. A. (1990). Expectancy models of alcohol use. Journal of Personality and Social Psychology, $58,918-928$.

Stevens, J. (1992). Applied multivariate statistics for the social sciences (2nd edition). Hillsdale: Lawrence Erlbaum.

Van de Luitgaarden, J., Wiers, R. W., Knibbe, R. A., \& Boon, B. J. (2006). From the laboratory to real life: A pilot study of an expectancy challenge with 'heavy drinking' young people on holiday. Substance Use and Misuse, 41, 353-368. 
Van Dijck, D., \& Knibbe, R. A. (2005). De prevalentie van probleemdrinken in Nederland [The prevalence of problem drinking in The Netherlands]. Maastricht: UM.

Wiers, R. W. (2002). Half full or half empty, what are we drinking? Some comments on the discussion of the causal role of alcohol expectancies as a mechanism of change. Addiction, 97, 599-600.

Wiers, R. W., Hoogeveen, K. J., Sergeant, J. A., \& Gunning, B. W. (1997). High- and low-dose alcohol-related expectancies and the differential associations with drinking in male and female adolescents and young adults. Addiction, 92, 871-888.

Wiers, R. W., Van de Luitgaarden, J., Van den Wildenberg, E., \& Smulders, F. T. Y. (2005). Challenging implicit and explicit alcohol-related cognitions in young heavy drinkers. Addiction, 100, 806-819.

Wiers, R. W., Van Woerden, N., Smulders, F. T. Y., \& De Jong, P. J. (2002). Implicit and explicit alcohol-related cognitions in heavy and light drinkers. Journal of Abnormal Psychology, 111, 648-658. 